\title{
Personal resilience and coping Part II: Identifying resilience and coping among U.S. military service members and veterans with implications for work
}

\author{
Valerie Rice ${ }^{\mathrm{a}, *}$ and Baoxia Liu $^{\mathrm{b}}$ \\ a Army Research Laboratory, Human Research \& Engineering Directorate, Army Medical Department Field \\ Element, Ft. Sam Houston, San Antonio, TX, USA \\ ${ }^{\mathrm{b}}$ DCS Corporation, Alexandria, VA, USA
}

Received 8 May 2015

Accepted 3 April 2016

\begin{abstract}
.
BACKGROUND: U.S. military personnel face challenging situations including frequent deployments, family separations, and exposure to war. Identifying coping strategies used by the most resilient service members and veterans could positively influence military resiliency training programs.

OBJECTIVE: The purposes of this paper are to investigate the relationship between coping and resilience among U.S. military active service members and veterans, to identify the coping strategies used by those considered most resilient, and to discuss coping and resilience as they relate to the workplace.

METHODS: U.S. military active service members and veterans $(N=191)$ completed a demographic survey and two selfreport questionnaires: The 14-Item Resilience Scale [1] and the Brief COPE [2].

RESULTS: Active duty service members had higher resilience scores than veterans $(p<0.05)$, but both fell into the moderate range. Coping strategies were not significantly different between the two groups $(p>0.05)$. Active service members' resilience was predicted by their use of positive reframing and less use of self-blame as coping strategies, accounting for $52.3 \%$ of the variance $\left(\mathrm{R}^{2}=0.523, \mathrm{~F}(2,60)=32.92, p=0.000\right)$. Veterans' resilience was predicted by longer time-in-service, greater use of humor, and less use of self-blame as coping strategies, explaining $44.8 \%$ of the variance $\left(R^{2}=0.448, F(3,116)=31.408\right.$, $p=0.000)$.

CONCLUSIONS: This research identifies the positive coping strategies, and least-used negative coping strategies, of the U.S. service members and veterans in our study population with higher resilience scores. Incorporating this information into military- or veteran-based resilience training is likely to increase training effectiveness.
\end{abstract}

Keywords: Positive reframing, self-blame, humor, time-in-service

\footnotetext{
*Address for correspondence: Valerie Rice, Army Research Laboratory HRED AMEDD Field Element, 3250 Koehler Rd,
} 


\section{Introduction}

Members of the U.S. military confront trials unique to their profession, especially during war. They are exposed to the horrors of war either by direct encounters or through the injuries and deaths of their fellow service members. Many service members deploy multiple times, often within short periods of time. In addition to exposure to combat itself, deployments bring prolonged family separations and require skills that may have only been employed during training exercises. Military life in general is stressful with frequent relocations, building new support systems with each move, long work hours, and the knowledge and reality that the mission always comes first.

Optimally, military service members are resilient, that is, they positively adapt when faced with challenges and adversity [3] (See Box 1). Positive adaptation refers to the ability to maintain equilibrium or 'bounce back' from trauma, without developing psychological or psychiatric pathology and without sacrificing functional capabilities or social appropriateness [4]. A description of personal resilience can be found in Rice and Liu [5], within this special edition of WORK.

\section{Box 1. Resilience defined.}

Resilience
is the ability of a person, who has been exposed to
a traumatic event, to maintain or quickly return to,
a healthy and stable state, physically, cognitively,
emotionally, and behaviorally.

Coping refers to taking action to deal life's problems, both large and small [6-9], and has been described as "constantly changing cognitive and behavioral efforts to manage specific external and/or internal demands that are appraised as taxing or exceeding the resources of the person" [6] (p. 141). While resilience refers to positive adaptation, coping techniques can be either positive (i.e., direct problem solving) or negative (i.e., avoidance or substance abuse). The relationship between coping and resilience warrants further investigation [5]. While it would seem that a person's ability to cope with life situations might promote their resilience, and that both coping and resilience may well impact one's ability to function successfully at work (and at home), these relationships have not been fully examined. The coping strategies of active duty and veteran populations, along with their potential impact on personal resilience have yet to be explored. The purposes of this paper are to examine the relationship between coping and resilience among a population of U.S. military active service members and veterans, including identifying their coping strategies, distinguishing the coping strategies used by those with the highest resiliency scores, and reviewing coping and resilience as they relate to the workplace.

\section{Methods}

U.S. military active duty service members and veterans were recruited as research volunteers from Joint Base San Antonio and the surrounding vicinity. Recruiting efforts included manning booths in Brooks Army Medical Center, outside the Post Exchange, and at military health fairs and at newcomers' exhibitions, as well as an email announcement at the U.S. Army Medical Department Center and School. Volunteers were recruited for a larger study investigating Mindfulness-Based Stress Reduction (MBSR) [10]. The data used for this paper was collected as part of the initial database, prior to MBSR intervention. The study was IRB approved and research volunteers read and completed an informed consent form prior to participation. Participants were not compensated for their participation.

\subsection{Self-assessment surveys}

Information for this paper includes self-reported demographics and responses to the 14-Item Resilience Scale (RS-14) [1] and Brief COPE [2].

\subsubsection{Demographics}

The self-report demographic questionnaire included questions about participants' background information, including age, race/ethnicity, gender, education, marital status, military status, military branch, deployment (i.e. whether they had deployed or not), and time-in-service. Time-in-service refers to the amount of time an individual was employed in active duty military service. Participants answered the questions using a computerized questionnaire created with Microsoft Access.

\subsubsection{The 14-Item Resilience Scale (RS-14)}

The 14-Item Resilience Scale (RS-14) [1] is a short version of the Resilience Scale (RS) [11]. The RS and the RS-14 measure resilience according to five essential interrelated components [1]: 
- Self-Reliance - "a belief in oneself and one's capabilities"

- Meaning - "the realization that life has a purpose and the valuation of one's contributions"

- Equanimity - "a balanced perspective of one's life and experiences"

- Perseverance - "the act of persistence despite adversity or discouragement"

- Existential Aloneness - "the realization that each person's life path is unique"

The RS-14 includes 14 items with a 7-point scale for each item $(1=$ strongly disagree, $7=$ strongly agree). The total score serves as an indication of a person's resilience. The RS-14 has high internal consistency reliability ( 0.93$)$ and convergent validity $(r=0.63)[1]$.

\subsubsection{Brief COPE}

The COPE Inventory seeks to measure various coping strategies within three major schemes: Problem-focused coping, emotion-focused coping, and dysfunctional coping [12]. This study used the Brief COPE inventory [2], an abbreviated version of the COPE inventory. The Brief COPE has 14 subscales with two items within each subscale. The time-limited format of the inventory was used, in which each item is in present perfect tense, to acquire participants' current coping mechanisms. The participants indicated the degree to which they used coping methods on a four point scale (i.e. $1=$ not at all, $2=$ a little bit, $3=$ medium amount, $4=a$ lot $)$. The test-retest reliabilities of Brief COPE subscales meet or exceed the minimal acceptable value of 0.50 [2]. The Brief COPE demonstrated good internal consistency $(\alpha>=0.72)$, adequate test-retest reliability $(r>=0.58, p<0.001)$ and acceptable convergent and concurrent validity when the items were grouped into emotion-focused, problem-focused, and dysfunctional subscales [13].

\subsection{Data analysis}

Data analyses were conducted with the IBM SPSS Statistics for Windows (Version 21, Armonk, NY: IBM Corp, Released 2012). Descriptive analyses included measures of frequency, percentage, range, mean and standard deviations for demographic information and the resilience and coping scores. Chi Square statistics were used to examine the differences in demographic distributions between military active service members and veterans. Statistical analyses, including independent-samples $T$-Test and Analysis of Variance (ANOVA), were used to examine the differences in mean values of demographic information between active service members and veterans, the differences in the resilience scores among demographic groups, and the use of the coping strategies among demographic groups. Post-hoc analyses using the Tukey HSD (Honestly Significant Difference) test were conducted to further examine significant differences found in the ANOVA analyses. Pearson Product Moment correlations were used to examine the relationships between resilience scores and certain demographic features (e.g. age, and time-in-service), between coping scores and certain demographic features (e.g. age and time-in-service), and between resilience and coping scores. Linear regression analyses were used to describe demographics and coping strategies that predicted resilience. A $p$-value of 0.05 was used to determine significance.

\section{Results}

\subsection{Demographics}

Table 1 shows the demographics of the participants $(n=191)$ grouped into active service members $(n=63,33.0 \%)$ and military veterans $(n=128$, $67.0 \%)$. Over half of the participants were male (52.9\%), Caucasian (54.5\%), and married (55.0\%). Most had at least some college education (93.2\%). Active service members and military veterans were not significantly different from one another in gender, ethnicity or marital status $(p>0.05)$. Differences in education level between groups (active vs. veteran) were not evaluated due to the small number of participants in the GED or high school diploma category for active service members. Participants' age ranged from 24 to 74 , with a mean and standard deviation of $48.42 \pm 12.23$. Active service members were younger $(38.87 \pm 7.98)$ than veterans $(53.12 \pm 11.19)(\mathrm{t}(189)=-10.10, p=0.00)$.

Table 2 shows the military-specific demographics. Participants primarily served in the U.S. Army (66.6\%) and had deployed (60.7\%). More active service members had deployed $(73.0 \%)$ compared with veterans $(54.7 \%)\left(\chi^{2}(1, N=191)=5.95\right.$, $p=0.015)$, and more active service members $(85.7 \%)$ than veterans $(57.0 \%)$ served in the U.S. Army $\left(\chi^{2}(2, N=191)=15.60, p=0.000\right)$. Two veteran participants did not answer the question about time-in-service, but for the remaining participants 
Table 1

Gender, education, ethnicity, and marital status demographics grouped by active service members and military veterans*

\begin{tabular}{|c|c|c|c|c|c|c|}
\hline & \multicolumn{2}{|c|}{ Active } & \multicolumn{2}{|c|}{ Veteran } & \multicolumn{2}{|c|}{ Total } \\
\hline & $\#$ & $\%$ & $\#$ & $\%$ & $\#$ & $\%$ \\
\hline \multicolumn{7}{|l|}{ Gender } \\
\hline Male & 32 & 50.8 & 69 & 53.9 & 101 & 52.9 \\
\hline Female & 31 & 49.2 & 59 & 46.1 & 90 & 47.1 \\
\hline \multicolumn{7}{|l|}{ Education } \\
\hline GED/high school & 0 & 0 & 13 & 10.2 & 13 & 6.8 \\
\hline $\begin{array}{l}\text { Some college/ } \\
\text { associate's }\end{array}$ & 20 & 31.7 & 38 & 29.7 & 58 & 30.4 \\
\hline Bachelors & 18 & 28.6 & 34 & 26.6 & 52 & 27.2 \\
\hline Masters/doctorate & 17 & 27.0 & 37 & 28.9 & 54 & 28.3 \\
\hline $\begin{array}{l}\text { Other profess- } \\
\text { ional degree }\end{array}$ & 8 & 12.7 & 6 & 4.7 & 14 & 7.3 \\
\hline \multicolumn{7}{|l|}{ Ethnicity } \\
\hline African American & 14 & 22.2 & 33 & 25.8 & 47 & 24.6 \\
\hline Native American & 1 & 1.6 & 3 & 2.3 & 4 & 2.1 \\
\hline Caucasian & 36 & 57.1 & 68 & 53.1 & 104 & 54.5 \\
\hline Hispanic & 9 & 14.3 & 21 & 16.4 & 30 & 15.7 \\
\hline Asian & 2 & 3.2 & 2 & 1.6 & 4 & 2.1 \\
\hline Other & 1 & 1.6 & 1 & 0.8 & 2 & 1.0 \\
\hline \multicolumn{7}{|l|}{ Marital Status } \\
\hline Married & 33 & 52.4 & 72 & 56.3 & 105 & 55.0 \\
\hline Divorced & 16 & 25.4 & 29 & 22.7 & 45 & 23.6 \\
\hline Widowed & 1 & 1.6 & 2 & 1.6 & 3 & 1.6 \\
\hline Single/separated & 12 & 19.0 & 20 & 15.6 & 32 & 16.8 \\
\hline $\begin{array}{l}\text { Living with } \\
\text { significant other }\end{array}$ & 1 & 1.6 & 5 & 3.9 & 6 & 3.1 \\
\hline Total & 63 & 100.0 & 128 & 100.0 & 191 & 100.0 \\
\hline
\end{tabular}

*Totals (\%) not reaching exactly 100 are due to rounding.

Table 2

Military related demographic information*

\begin{tabular}{|c|c|c|c|c|c|c|}
\hline & \multicolumn{2}{|c|}{ Active } & \multicolumn{2}{|c|}{ Veteran } & \multicolumn{2}{|c|}{ Total } \\
\hline & $\#$ & $\%$ & $\#$ & $\%$ & $\#$ & $\%$ \\
\hline \multicolumn{7}{|l|}{ Military Branches ** } \\
\hline Army & 54 & 85.7 & 73 & 57.0 & 127 & 66.5 \\
\hline Air Force & 5 & 7.9 & 32 & 25.0 & 37 & 19.4 \\
\hline Navy/Marines/ Coast Guard & 4 & 6.3 & 23 & 18.0 & 27 & 14.1 \\
\hline \multicolumn{7}{|l|}{ Has been deployed** } \\
\hline Yes & 46 & 73.0 & 70 & 54.7 & 116 & 60.7 \\
\hline No & 17 & 27.0 & 58 & 45.3 & 75 & 39.3 \\
\hline Total & 63 & 100.0 & 128 & 100.0 & 191 & 100.0 \\
\hline
\end{tabular}

*Totals (\%) not reaching exactly 100 are due to rounding. ** $p<0.01$.

( $n=189$ ), time-in-service ranged from 1 to 34 years, with an average of 15.44 years $( \pm 8.6)$. There was no time-in-service difference between active service members (15.65 years \pm 8.05$)$ and veterans $(15.34$ years \pm 8.89$)(p>0.05)$

\subsection{Resilience}

The resilience scores of all the participants ranged from 21 to 98 with a mean and stan-

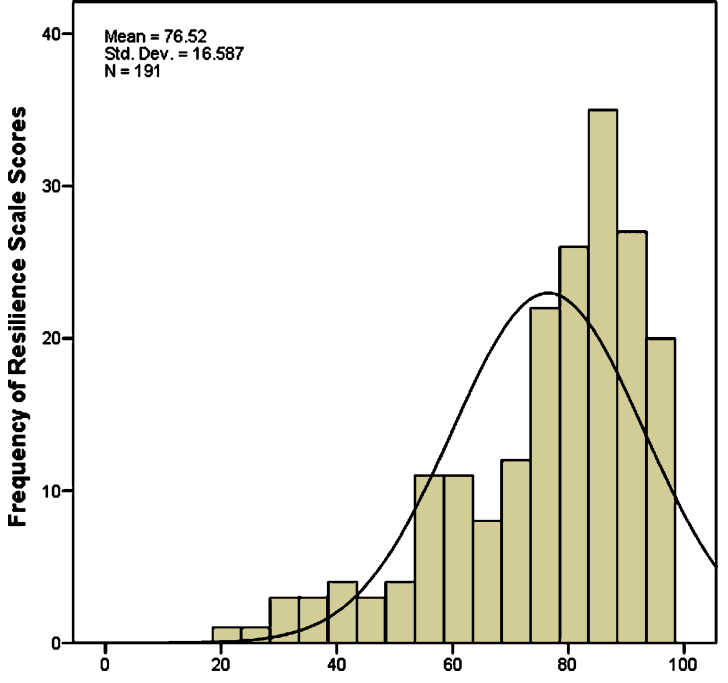

Fig. 1. The distribution of RS-14 resilience scores for all the participants.

dard deviation of $76.52 \pm 16.59$. The distribution of the resilience scores was negatively skewed (see Fig. 1). Active service members $(80.56 \pm 15.31)$ had higher resilience scores than veterans $(74.54 \pm 16.88)$ $(\mathrm{t}(189)=2.39, p=0.018)$. Means and standard deviations of resilience scores among education levels are shown in Table 3. Higher education levels had greater mean resilience scores $(\mathrm{F}(4,186)=5.56$, $p=0.000)$. Post-hoc analysis showed significant differences in resilience between GED/high school and bachelor's degree, between GED/high school and master's/doctoral degree, and between some college/associate degree and master/doctoral degree. Pearson Product Moment correlations between resilience scores and time-in-service and between resilience and age were investigated. The more time spent on active duty, the higher the resilience score ( $r=0.24, N=189, p=0.001)$, however there was no significant correlation between resilience and age $(p>0.05)$. Gender, ethnicity, marital status, military branch, and deployment experience did not show significant differences in resilience scores $(p>0.05)$.

Because of the significant differences between active service members and veterans, the data from the two groups were analyzed independently in subsequent analyses. The distributions of the resilience scores for active service members and veterans were also negatively skewed (Figs. 2 and 3). For active service members, resilience scores were not different among the demographic groups (i.e. age, ethnicity, gender, education, marital status, military branch, deployment and time in service) 
Table 3

Significant differences in resilience scores among education levels

\begin{tabular}{lccc}
\hline & $\mathrm{N}$ & Mean & Std. Deviation \\
\hline Education Level $^{* *}$ & & & \\
$\quad$ GED/ high school & 13 & 64.23 & 16.804 \\
Some college/associate degree & 58 & 72.02 & 19.242 \\
Bachelors & 52 & 78.88 & 13.479 \\
Master's/doctoral degree & 54 & 82.70 & 13.216 \\
Other professional degree & 14 & 74.00 & 16.807 \\
${ }^{* *} p<0.01$. & & &
\end{tabular}

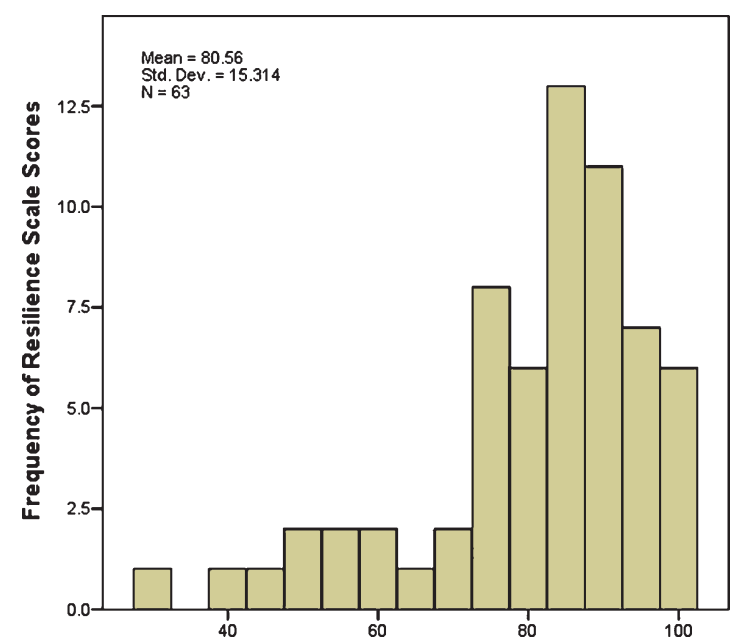

Fig. 2. The distribution of RS-14 resilience scores for active service members.

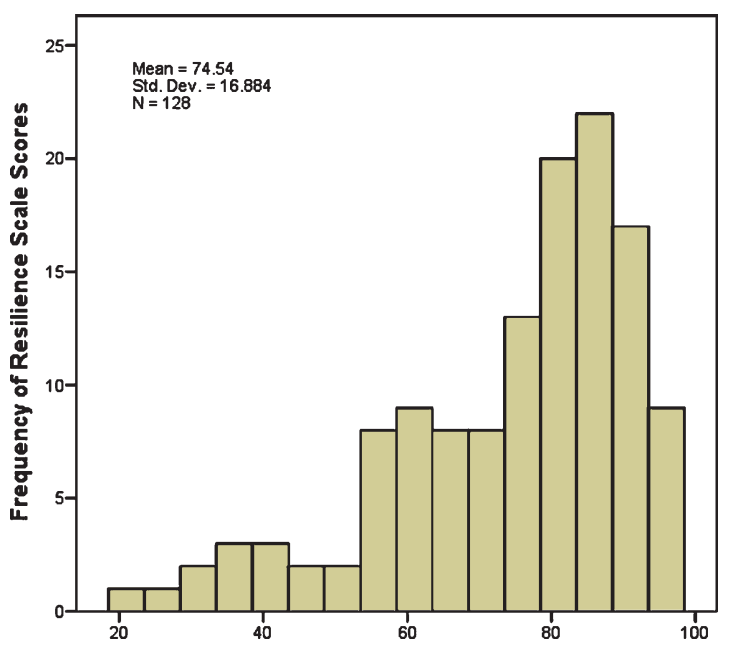

Fig. 3. The distribution of RS-14 resilience scores for veterans.

$(p>0.05)$. For veterans, resilience scores varied with education level and time-in-service $(p<0.05)$, but not for the other demographic features (i.e. age, ethnicity, gender, marital status, military branch,
Table 4

Veterans' resilience scores among education levels

\begin{tabular}{lccc}
\hline & $\mathrm{N}$ & Mean & Std. Deviation \\
\hline Education Level** $^{*}$ & & & \\
GED/ high school & 13 & 64.23 & 16.804 \\
Some college/associate degree & 38 & 70.08 & 20.003 \\
Bachelors & 34 & 78.88 & 12.138 \\
Master's/doctoral degree & 37 & 80.43 & 13.789 \\
Other professional degree & 6 & 64.17 & 17.860 \\
Total & 128 & 74.54 & 16.884 \\
${ }^{* *} p<0.01$. & & &
\end{tabular}

and deployment) $(p>0.05)$. Resilience scores differed significantly among education levels $(\mathrm{F}(4$, $123)=4.598, p=0.002$ ), with post-hoc analysis indicating that veterans with GED/high school education had lower resilience scores than veterans with bachelors, or with master/doctoral degree (see Table 4). For veterans, the longer the time-in-service, the higher the resilience score $(r=0.354, n=126, p=0.000)$.

\subsection{Coping}

The Brief COPE subscale scores were not significantly different between active service members and veterans $(p>0.05$, see Table 5$)$. The most frequently used (highest scoring) five coping strategies for both populations combined were: acceptance, positive reframing, religion, active coping and planning. The least used coping strategies were: denial, substance abuse, and behavioral disengagement.

The Brief COPE subscale scores were compared between groups separately for active service members and veterans. For active service members, the Brief COPE subscale scores varied with age, ethnicity, gender, and marital status $(p<0.05)$, but not with education level, military branch, deployment, or time-in-service $(p>0.05)$. Age was correlated with only one coping strategy, with younger service members using more emotional support than older service members $(r=-0.249$, $n=63, p=0.049$ ). Table 6 shows the coping scores that differed by ethnicity, gender, and marital status. Post-hoc analyses indicated that African Americans used religion-based coping more than Hispanic participants, females used positive reframing more than males, and divorced participants used acceptance more than married participants $(p<0.05)$.

For veterans, coping strategies varied with age, gender, education level, military branch, and time-inservice $(p<0.05)$, but not with ethnicity, marital sta- 
Table 5

Brief COPE subscale scores of U.S. military active service members and veterans

\begin{tabular}{lcccc}
\hline & \multicolumn{2}{c}{ Active } & \multicolumn{2}{c}{ Veteran } \\
\cline { 2 - 3 } Mean & Std. Deviation & & Mean & Std. Deviation \\
\hline Emotion-focused Coping & & & & \\
$\quad$ Acceptance & 5.49 & 1.655 & 5.56 & 1.591 \\
Emotional Support & 4.86 & 1.933 & 4.61 & 1.824 \\
$\quad$ Humor & 4.11 & 1.797 & 3.80 & 1.867 \\
$\quad$ Positive Reframing & 5.54 & 1.941 & 5.09 & 1.745 \\
$\quad$ Religion & 5.06 & 2.162 & 5.16 & 2.236 \\
Problem-focused Coping & & & & \\
$\quad$ Active Coping & 5.32 & 1.758 & 5.32 & 1.779 \\
$\quad$ Planning & 5.60 & 1.612 & 5.27 & 1.609 \\
$\quad$ Instrumental Support & 4.83 & 1.728 & 4.67 & 1.806 \\
Dysfunctional Strategies & & & & \\
$\quad$ Denial & 2.78 & 1.408 & 2.66 & 1.239 \\
$\quad$ Self-Distraction & 4.73 & 1.648 & 4.80 & 1.665 \\
$\quad$ Substance Abuse & 2.71 & 1.396 & 2.77 & 1.411 \\
Behavioral Disengagement & 2.86 & 1.424 & 3.09 & 1.480 \\
$\quad$ Self-Blame & 4.38 & 1.930 & 4.66 & 1.989 \\
$\quad$ Venting & 4.10 & 1.624 & 4.28 & 1.436 \\
\hline
\end{tabular}

Table 6

Significantly different Brief COPE subscale scores across demographic groups for U.S. military active service members

\begin{tabular}{lcccc}
\hline $\begin{array}{c}\text { Demographic } \\
\text { groups }\end{array}$ & $\begin{array}{c}\text { COPE } \\
\text { subscale }\end{array}$ & $\begin{array}{r}\text { Mean } \\
\text { Deviation }\end{array}$ & $\begin{array}{c}\text { Significant } \\
\text { Statistics }\end{array}$ \\
\hline $\begin{array}{l}\text { Ethnicity } \\
\text { Dfrican American }\end{array}$ & Religion** & 6.21 & 1.805 & $\mathrm{~F}(2,56)=5.551$, \\
$\quad$ & 4.89 & 2.108 & $p=0.006$ \\
Caucasian & & 3.44 & 1.509 & \\
Hispanic & & & &
\end{tabular}

Gender

\begin{tabular}{|c|c|c|c|c|}
\hline & $\begin{array}{l}\text { Positive } \\
\text { Reframing** }\end{array}$ & & & \\
\hline Females & & 6.19 & 1.815 & $\mathrm{t}(61)=2.769$ \\
\hline Males & & 4.91 & 1.873 & $p=0.007$ \\
\hline
\end{tabular}

Marital Status ${ }^{2}$

\begin{tabular}{|c|c|c|c|}
\hline \multicolumn{4}{|c|}{ Acceptance* $^{*}$} \\
\hline Married & 5.00 & 1.581 & $\mathrm{~F}(2,58)=3.971$, \\
\hline Divorced & 6.31 & 1.580 & $p=0.024$ \\
\hline Single/Separated & 5.83 & 1.642 & \\
\hline
\end{tabular}

${ }^{* *} p<0.01,{ }^{*} p<0.05 .{ }^{1}$ Four participants were removed from the analysis due to three categories having less than 3 participants: Native American, Asian, and other. ${ }^{2}$ Two participants were removed from the analysis due to one category having less than 3 participants: Widowed and living with significant other.

tus, or deployment $(p>0.05)$ (Table 7). Older age in veterans was associated with greater use of religionbased coping and decreased use of self-distraction, substance use, behavioral disengagement, and selfblame. More time spent in active military service was related to less use of self-distraction, substance use, and self-blame $(p<0.05)$. Table 8 shows the significant results for veterans' coping scores with demographics. Female veterans used more positive reframing and more self-distraction than male
Table 7

Significant correlations of Brief COPE subscale scores with age and with time-in-service for U.S. military veterans

\begin{tabular}{|c|c|c|c|}
\hline $\begin{array}{l}\text { Pearson } \\
\text { correlation }\end{array}$ & $\begin{array}{l}\text { Correlation } \\
\text { with Age }\end{array}$ & $\begin{array}{l}\text { Sample } \\
\text { size }(\mathrm{N})\end{array}$ & $\begin{array}{c}\text { Sig. } \\
\text { (2-tailed) }\end{array}$ \\
\hline Religion & $0.250^{* *}$ & 128 & 0.004 \\
\hline Self-Distraction & $-0.350 * *$ & 128 & 0.000 \\
\hline Substance Abuse & $-0.219^{*}$ & 128 & 0.013 \\
\hline Behavioral Disengagement & $-0.238^{* *}$ & 128 & 0.007 \\
\hline \multirow[t]{2}{*}{ Self-blame } & $-0.176^{*}$ & 128 & 0.047 \\
\hline & $\begin{array}{l}\text { Correlation with } \\
\text { Time-in-service }\end{array}$ & $\begin{array}{l}\text { Sample } \\
\text { size }(\mathrm{N})\end{array}$ & $\begin{array}{c}\text { Sig. } \\
\text { (2-tailed) }\end{array}$ \\
\hline Self-Distraction & $-0.197^{*}$ & 126 & 0.027 \\
\hline Substance Use & $-0.257^{* *}$ & 126 & 0.004 \\
\hline Self-Blame & $-0.232^{* *}$ & 126 & 0.009 \\
\hline
\end{tabular}

${ }^{*} p<0.05$. ${ }^{* *} p<0.01$.

veterans $(p<0.05)$. Those with a masters/doctoral degree used less self-blame than three other education levels - some college/associate, bachelors, and other professional degree $(p<0.05)$. Although the trend showed that veterans with a masters/doctoral degree used less self-blame than those with GED/high school diploma, the statistics did not show significant result in the post-hoc analysis. Army veterans used less instrumental support than Air Force veterans $(p<0.05)$.

\subsection{Coping and resilience}

Correlations between coping and resilience were investigated for active service members and veterans separately. Higher resilience scores were associated with using more acceptance and positive reframing coping strategies, and less behavioral disengagement 
Table 8

Significantly different Brief COPE subscale scores across demographic groups for military veterans

\begin{tabular}{|c|c|c|c|c|}
\hline $\begin{array}{l}\text { Demographic } \\
\text { groups }\end{array}$ & $\begin{array}{c}\text { COPE } \\
\text { subscale }\end{array}$ & Mean & $\begin{array}{c}\text { Std. } \\
\text { Deviation }\end{array}$ & $\begin{array}{c}\text { Significant } \\
\text { Statistics }\end{array}$ \\
\hline \multicolumn{5}{|l|}{ Gender } \\
\hline & $\begin{array}{l}\text { Positive } \\
\text { Reframing* }\end{array}$ & & & \multirow{3}{*}{$\begin{array}{c}\mathrm{t}(126)=2.539 \\
p=0.012\end{array}$} \\
\hline Females & & 5.51 & 1.612 & \\
\hline \multirow[t]{2}{*}{ Males } & & 4.74 & 1.788 & \\
\hline & $\begin{array}{l}\text { Self- } \\
\text { Distraction** }\end{array}$ & & & \multirow{3}{*}{$\begin{array}{c}\mathrm{t}(126)=3.749 \\
p=0.000\end{array}$} \\
\hline Females & & 5.37 & 1.691 & \\
\hline Males & & 4.32 & 1.490 & \\
\hline \multicolumn{5}{|l|}{ Education } \\
\hline & Self-blame** & & & \multirow{6}{*}{$\begin{array}{c}\mathrm{F}(4,123)=4.258 \\
p=0.003\end{array}$} \\
\hline GED/ high school & & 5.31 & 2.136 & \\
\hline Some college /Associate degree & & 4.87 & 1.920 & \\
\hline Bachelors & & 5.06 & 1.890 & \\
\hline Master's /Doctoral degree & & 3.65 & 1.798 & \\
\hline Other professional degree & & 6.00 & 1.789 & \\
\hline \multicolumn{5}{|l|}{ Military Branches } \\
\hline & $\begin{array}{l}\text { Instrumental } \\
\text { support* }\end{array}$ & & & \multirow{4}{*}{$\begin{array}{c}\mathrm{F}(2,125)=4.047 \\
p=0.020\end{array}$} \\
\hline Army & & 4.34 & 1.701 & \\
\hline Air Force & & 5.41 & 1.701 & \\
\hline Navy/Marines/Coast Guard & & 4.70 & 2.032 & \\
\hline
\end{tabular}

Table 9

Correlations between resilience and coping scores for active service members and veterans

\begin{tabular}{lcl}
\hline Pearson correlation & Active $(\mathrm{N}=63)$ & Veteran $(\mathrm{N}=128)$ \\
\hline Emotion-focused Coping & & \\
Acceptance & $0.288^{*}$ & $0.340^{* *}$ \\
Emotional Support & 0.210 & 0.124 \\
Humor & 0.210 & $0.286^{* *}$ \\
Positive Reframing & $0.389^{* *}$ & $0.416^{* *}$ \\
$\quad$ Religion & 0.114 & $0.265^{* *}$ \\
Problem-focused Coping & & \\
$\quad$ Active Coping & 0.196 & $0.201^{*}$ \\
Planning & -0.016 & $0.194^{*}$ \\
$\quad$ Instrumental Support & 0.068 & 0.030 \\
Dysfunctional Strategies & & \\
$\quad$ Denial & -0.174 & $-0.227^{* *}$ \\
Self-Distraction & -0.144 & -0.100 \\
$\quad$ Substance Abuse & -0.164 & $-0.176^{*}$ \\
$\quad$ Behavioral Disengagement & $-0.556^{* *}$ & $-0.445^{* *}$ \\
Self-Blame & $-0.648^{* *}$ & $-0.510^{* *}$ \\
$\quad$ Venting & -0.194 & $-0.242^{* *}$ \\
\hline${ }^{*} p<0.05,{ }^{* *} p<0.01$. & &
\end{tabular}

and self-blame strategies for both active service members and veterans $(p<0.05$, see Table 9). Veterans' higher resilience scores were also associated with greater usage of humor, religion, active coping, and planning, and less use of denial, substance abuse, and venting.

\subsection{Prediction of resilience}

Regression analyses were conducted to further investigate the relationship between demographics, coping, and resilience. Demographics and coping strategies found to be associated with resilience $(p<0.05)$ were entered into the first set of regression analyses.

Table 10 shows the results of the regression analysis for active service members, with $56.5 \%$ of the variance being explained by the demographics and coping scores $\left(\mathrm{R}^{2}=0.565, \mathrm{~F}(8,54)=9.80\right.$, $p=0.000)$. However, only greater positive reframing and less self-blame contributed significantly to the prediction of higher resilience $(p<0.05)$, therefore they were entered into a separate regression to predict resilience, explaining $52.3 \%$ of the variance $(\mathrm{F}(2$, $60)=32.924, p<0.000$ )

Table 11 shows the regression results for military veterans, with $60.1 \%$ of the variance being explained by the demographics and coping scores $\left(\mathrm{R}^{2}=0.601\right.$, $\mathrm{F}(16,103)=9.692, p=0.000)$. However, only timein-service and the coping strategies of humor and self-blame contributed significantly to the equation. Consequently, these variables were entered into a regression to predict resilience and were found to 
Table 10

Predicting resilience from demographic variables and coping Strategies for U.S. service members

\begin{tabular}{|c|c|c|c|c|c|}
\hline \multirow[t]{2}{*}{ Variables } & \multicolumn{2}{|c|}{$\begin{array}{c}\text { Unstandardized } \\
\text { Coefficients }\end{array}$} & \multirow{2}{*}{$\begin{array}{c}\text { Standardized } \\
\text { Coefficients } \\
\text { Beta }\end{array}$} & \multirow[b]{2}{*}{$\mathrm{t}$} & \multirow[b]{2}{*}{ Sig. } \\
\hline & $\mathrm{B}$ & Std. Error & & & \\
\hline Constant & 98.981 & 11.372 & & 8.704 & 0.000 \\
\hline \multicolumn{6}{|l|}{ Demographic Variables } \\
\hline Age & -0.280 & 0.185 & -0.146 & -1.513 & 0.136 \\
\hline \multicolumn{6}{|l|}{ Gender } \\
\hline$(1=$ male $; 2=$ female $)$ & 0.784 & 2.982 & 0.026 & 0.263 & 0.794 \\
\hline $\begin{array}{l}\text { Ethnicity } \\
\qquad \begin{array}{l}\text { (1= African American; } \\
\text { 2= Native American; } \\
3=\text { Caucasian } ; 4=\text { Hispanic; } \\
\text { 5= Asian; } 6=\text { other })\end{array}\end{array}$ & 0.790 & 1.218 & 0.062 & 0.649 & 0.519 \\
\hline $\begin{array}{l}\text { Marital Status } \\
\qquad \begin{array}{l}\text { (1= married; } 2=\text { divorced; } \\
3 \text { = widowed; } \\
4=\text { single/separated; } \\
\text { 5= partnered/living with } \\
\text { significant other })\end{array}\end{array}$ & 0.263 & 1.758 & 0.021 & 0.149 & 0.882 \\
\hline \multicolumn{6}{|l|}{ Emotion-focused Coping } \\
\hline Acceptance & -0.147 & 1.129 & -0.016 & -0.130 & 0.897 \\
\hline Positive Reframing* & 2.172 & 0.956 & 0.275 & 2.271 & 0.027 \\
\hline \multicolumn{6}{|l|}{ Dysfunctional Coping } \\
\hline Behavioral Disengagement & -2.047 & 1.284 & -0.190 & -1.594 & 0.117 \\
\hline Self-Blame ${ }^{* *}$ & -4.331 & 0.912 & -0.546 & -4.747 & 0.000 \\
\hline
\end{tabular}

${ }^{*} p<0.05,{ }^{* *} p<0.01$.

Table 11

Predicting resilience from demographic variables and coping strategies for military veterans

\begin{tabular}{|c|c|c|c|c|c|}
\hline \multirow[t]{2}{*}{ Variables } & \multicolumn{2}{|c|}{$\begin{array}{c}\text { Unstandardized } \\
\text { Coefficients }\end{array}$} & \multirow{2}{*}{$\begin{array}{c}\text { Standardized } \\
\text { Coefficients } \\
\text { Beta }\end{array}$} & \multirow[b]{2}{*}{$\mathrm{t}$} & \multirow[b]{2}{*}{ Sig. } \\
\hline & $\mathrm{B}$ & Std. Error & & & \\
\hline Constant & 58.686 & 10.579 & & 5.547 & 0.000 \\
\hline \multicolumn{6}{|l|}{ Demographic Variables } \\
\hline Age & 0.020 & 0.115 & 0.013 & 0.170 & 0.865 \\
\hline \multicolumn{6}{|l|}{ Gender } \\
\hline$(1=$ male $; 2=$ female $)$ & -1.836 & 2.598 & -0.055 & -0.707 & 0.481 \\
\hline Time-in-service ${ }^{* *}$ & 0.392 & 0.140 & 0.210 & 2.806 & 0.006 \\
\hline \multicolumn{6}{|l|}{ Education } \\
\hline $\begin{array}{l}(1=\mathrm{GED} / \text { high school; } \\
2=\text { some college/associate } \\
\text { degree; } 3 \text { = bachelors; } \\
4 \text { = master's/doctoral degree })\end{array}$ & 1.321 & 1.314 & 0.079 & 1.005 & 0.317 \\
\hline \multicolumn{6}{|l|}{ Military Branch } \\
\hline $\begin{array}{l}(1=\text { army }, 2=\text { air force } \\
3=\text { navy/marines/coast guard })\end{array}$ & 0.134 & 1.526 & 0.006 & 0.088 & 0.930 \\
\hline \multicolumn{6}{|l|}{ Emotion-focused Coping } \\
\hline Acceptance & 1.627 & 0.830 & 0.156 & 1.959 & 0.053 \\
\hline Humor** & 2.734 & 0.612 & 0.297 & 4.469 & 0.000 \\
\hline Positive Reframing & 1.205 & 0.825 & 0.126 & 1.460 & 0.147 \\
\hline Religion & 0.203 & 0.594 & 0.027 & 0.342 & 0.733 \\
\hline \multicolumn{6}{|l|}{ Problem-focused Coping } \\
\hline Active Coping & -0.235 & 0.910 & -0.025 & -0.258 & 0.797 \\
\hline Planning & 1.438 & 1.087 & 0.136 & 1.323 & 0.189 \\
\hline \multicolumn{6}{|l|}{ Dysfunctional Coping } \\
\hline Denial & -0.508 & 1.055 & -0.037 & -0.482 & 0.631 \\
\hline Substance Abuse & 0.171 & 0.802 & 0.015 & 0.214 & 0.831 \\
\hline Behavioral Disengagement & -1.358 & 0.960 & -0.122 & -1.414 & 0.160 \\
\hline Self-Blame** & -3.406 & 0.699 & -0.405 & -4.870 & 0.000 \\
\hline Venting & -0.942 & 0.878 & -0.080 & -1.073 & 0.286 \\
\hline
\end{tabular}


account for $44.8 \%$ of the variance $\left(\mathrm{R}^{2}=0.448, \mathrm{~F}(3\right.$, $116)=31.408, p=0.000)$.

\section{Discussion}

\subsection{Demographic findings}

Demographic findings of participants being primarily affiliated with the U.S. Army are expected, given our primary research site on Ft. Sam Houston, an Army post. The younger age of the active military population, compared with veterans is also expected for two reasons. First, active duty participants are unlikely to have reached an age or career status that would make them eligible for retirement, and most participating veterans were retirees. Although any military veteran eligible for medical benefits could participate in the research, more career veterans are likely to reside in the San Antonio area, than younger service-connected disability retirees, thus the veteran population would likely be older than the active service population. The greater number of deployments among the active service population may be indicative of the recent involvement in Afghanistan and Iraq. Data from 2011 indicated that $73 \%$ of active military soldiers had deployed to Afghanistan or Iraq, with most of those who had not deployed being newer recruits who were not yet eligible to deploy [14]. According to the report, "the Army retains very little unutilized capacity to deploy additional active component soldiers..." (p. 1).

\subsection{Resilience}

The distributions of resilience scores for all the participants, for active service members only and veterans only were negatively skewed. The results are very similar to the results based on a sample size of 1161 participants who answered the RS-14 online [1] (Mean =76.17, Std = 13.9). Other research also showed a negative skew in the distribution of resilience [15].

While the average resilience score was higher for active service members than veterans, both scores fell within the moderate range [1]. Demographic differences in resilience occurred for veterans only, demonstrating higher resilience scores among those with a higher education and longer time-in-service. Higher education has long been associated with both psychological and physical health [16], possibly interrelated with socio-economic status $[17,18]$. No other research was found that investigated whether this seeming protective effect of education on health was also shown in terms of resilience, and whether it is the educational level itself, the associated health status, or both that might positively impact resilience. The positive relationship between veterans' time-inservice and resilience may indicate that veterans' experiences in the military and after the military may have impacted resilience [5]. Since active service members are still in service, the effect of military experience on resilience is still an on-going process.

\subsection{Coping}

Coping strategies were similar between active U.S. service members and veterans. The five highest scores for both groups were all action-based, and included three emotion-focused strategies - acceptance, positive reframing, and religion, and two problem-focused strategies - active coping and planning. These coping strategies likely tell the story of the participants' experiences, as well as the strengths they may bring to a work setting. In Rice and Liu's article on personal resilience, Part I of this series [5], they display coping strategies and an abbreviated description of how each strategy might impact a person within their work setting. Further exploration of each frequently used coping strategy is included below.

Previous research has noted that active service members relied on avoidance coping when they did not have much control over their environment, especially during deployment $[19,20]$. Our research did not show frequent use of avoidance coping among either active service or veteran populations, perhaps in part, because our data was collected during nondeployment.

Emotion-focused coping aims to reduce the emotional distress caused by a stressor [12]. This type of coping is often selected when an individual assesses the stressful situation as something they cannot alter [12]. Acceptance, as an emotion-focused coping technique, requires an individual to first accept the reality of the stressor or situation as it is, and then to accept their inability to change their circumstances. Acceptance is a functional strategy in conditions that require adaptation or endurance. For individuals in the military, there are a number of circumstances that fall within this description. For example, most military service members have minimal input into their assignment locations, their job requirements at a par- 
ticular assignment, the work hours or shifts, and the amount of time they will spend in an assignment. They cannot choose to leave their job or assignment at their own will, do not have a voice in who their supervisor(s) will be, and typically cannot select the service members who will work with or for them. Written Standard Operating Procedures dictate the parameters within which most work will be conducted, and centralized oversight determines the pay that will be received, the travel that will occur, and the types of behavior towards one another that is required. While that may sound rather dismal, it actually creates an atmosphere for immense growth in terms of one's ability to adapt to new situations, people, places, and work demands. Accepting the reality of a relatively impenetrable work-related situation opens the door for examination of uncommon and imaginative solutions, without complaint. With acceptance also comes the realization that complaints are futile, but there are many roads to successful resolution (including rewriting regulations). In terms of one's health, acceptance as a coping strategy can be helpful for chronic conditions, such as chronic pain. With acceptance, an individual can move from having their focus on how they feel, fighting the pain or working directly to change their pain, to focus instead on function and life activities [21].

Positive reframing is known as positive reinterpretation, positive reappraisal, benefit finding, and meaning making $[12,22]$. Similarly, positive reframing is an emotion-focused coping strategy aimed at managing the emotional distress resulting from a stressor perceived to be outside of one's control. An individual using this technique construes the stressor, the resulting stress, and/or the stress-related outcomes in positive terms, even though they previously viewed them negatively. Positive reframing is a proactive approach that permits an individual to have control over his reaction to a stressor by reframing it into a potential growth experience. Following Frederickson's "broaden and build" theory, positive perceptions broaden an individual's responses, encouraging personal resourcefulness in terms of ideas and actions [23]. Once again this type of coping is an effective measure when an individual does not believe she can directly change the stressful conditions, such as those that readily occur within a military environment. As an accommodative coping strategy, positive reframing works particularly well for those with perfectionistic strivings [24]. Although military individuals themselves may not be perfectionists, the military system is well-organized with a complex series of regulations and measures to guide and ensure high quality performance. Turning what might be perceived as a difficult and negative situation into a positive learning experience, with the broadening and building gains resulting both for the task at hand and for the individual would seem wellsuited for the military population. Positive reframing can also serve as a mechanism to introduce gratitude and decrease symptoms of depression [25]. In a work setting, individuals who turn perceived insurmountable challenges into positive growth experiences are likely to be able to hear and relate to others' pointsof-view, encourage team members, bolster morale, and identify unique solutions to problems. Together, acceptance and positive reframing appear to be a powerful combination. Accepting the reality of a situation, defining it positively, and using the opportunity to develop novel in-roads to problem solving the challenges at-hand are desirable traits in any setting. In terms of health, acceptance and positive reframing predicted greater functional, emotional and physical well-being, as well as a higher quality of life, one year post gynecologic cancer diagnosis [26].

The final frequently used emotion-based coping method among active military and veterans is the use of religion as a coping strategy. Involvement with one's religious faith is associated with physical and psychological well-being and with coping with adversity [27]. The U.S. military services have religious professionals, qualified as civilian pastors (ordained clergy) and commissioned as officers, among their ranks. In early 2013, there were approximately 3,000 Chaplains on active duty in the U.S. Army, Navy, and Air Force, representing 175 different denominations [28]. Their duties include providing religious ministry in their own, and in other, traditions to service members and their families. Thus, should a U.S. military service member choose to avail themselves of services, religious leadership and counsel are available. The business of the military is a serious one and questions of mortality and morality arise readily [28], and one's religious beliefs can serve as a guide during such questioning. Sterner and Jackson-Cherry found that spiritual and religious beliefs prior to U.S. service members' deployment was not a significant predictor of their coping during deployment, however Christian affiliation and the frequency of one's engagement in spiritual and religious practices were significant predictors of coping, along with support and age [29]. While religion-based coping can help in a number of difficult personal situations, the relationship between 
one's belief systems and their ability to cope with life is complex, and these beliefs can impact coping in either positive or negative ways. For example, positive religion-based coping following divorce has been shown to be predictive of post-traumatic growth, while negative religion-based coping was predictive of greater depressive symptoms under situations such as divorce [30, 31], as well as among those in high stress jobs, including clinical nursing [32].

The two problem-focused coping strategies with the highest scores for military service members and veterans were active coping and planning. Both coping mechanisms reflect direct action to alter the source of the stress, and enforce the belief that constructive change is possible [12]. Planning involves thinking about the methods and steps to ameliorate the stressor, while active coping activates the plan. While it would seem the two might always coexist, this is not necessarily the case. An individual who does not plan, but takes immediate action might be impulsive in their decision making or action, while someone who plans well might have difficulty with execution. Military work involves a great deal of planning, from recruiting and training operations, to the logistics of deploying personnel, equipment, and supplies. Once action plans are well in place, they are completed by military personnel, with each rank and military occupational specialty stepping in to accomplish their specific tasks. Sequential forecasting occurs years in advance for all aspects of military involvement, with such planning often bringing in subject matter experts from civilian and military sectors to build on current knowledge, project future needs, and take proactive action. In terms of work environments, active coping has been associated with 'protean careers', in which an individual drives their career based on their own mental success and decision making, rather than on a set of standards or structures of an organization, as well as with 'boundaryless careers', independent of typical organizational and social boundaries [33]. Active coping has also been associated with positive job search behavior, performance, career success, and psychological well-being $[33,34]$.

Thus, the findings in this paper regarding coping strategies appear to fit the participants' work-related experiences. In addition, these findings, along with information found in the open literature, yield information as to the strengths that military service members and veterans may bring to a workplace.

Our results demonstrated that coping strategies differed according to demographics among active
U.S. service members and veteran populations. For those engaged in active military service, the findings regarding ethnicity, gender, and marital status and coping strategies appear unique and may warrant further study. That younger service members used more emotional support than older service members appears to fit the situation, in which many young recruits enter the military from high school and may initially depend heavily on family and friends for emotional support. Older service members will have advanced in rank, and while emotional support may remain important, there is often less opportunity to turn to others for such support. This echoes the saying 'it's lonely at the top' - meaning that individuals of higher rank often shoulder responsibilities without having an active support system of individuals who are even aware of the complexities of their work or their lives.

Overall, the veteran population was older than the active service population. Veterans used more religion and less self-destructive, dysfunctional coping strategies of self-distraction, substance abuse, behavioral disengagement, and self-blame than younger veterans, but this same finding did not occur among the active duty population. These findings support research identifying healthier coping occurring with age $[35,36]$, as well as aging being associated with more positive emotional well-being and stability [37]. While similar coping strategies can occur across age groups, older individuals tend to use less avoidance strategies [35] and more active problem solving [36] until old age when dementia may begin [38].

Women used more positive reframing than men among both active service members and veterans, and female veterans used more self-distraction than male veterans. As previously mentioned, positive reframing is considered a form of emotion-focused coping, in which the aim of the coping strategy is to alleviate the associated emotional distress as the stressor is not believed to be within the individual's control. Prior research shows women use more emotionfocused coping and avoidance than men [38], as well as more social support [39]. As positive reframing is a subcomponent of emotion-focused coping and self-distraction is method of avoidance, our findings support gender differentiations shown in earlier studies on coping.

Among veterans, our findings appear to demonstrate that those with a higher education use less self-blame than those with less education, however little could be found in the open literature associating education level with coping strategies. In addition, the 
findings regarding "other professional degree" must be handled with care, as it is uncertain how participants may have interpreted the term. Finally, we are unaware of any research comparing coping strategies across services to assist in explaining why Army veterans might be less inclined to ask for advice than Air Force veterans. Research on instrumental support at work showed that receiving imposed instrumental support elicited negative reactions, unless the problem was considered unsolvable by those receiving the advice [40]. Seeking instrumental support may be viewed differently in the various military service branches, based on the culture of each.

\subsection{Predicting resilience using coping strategies}

\subsubsection{Prediction of resilience among active service members}

A greater use of positive reframing and less use of self-blame were predictive of higher resilience among active service members. Positive reframing has been discussed previously in this article and is an emotion-focused approach. Importantly, when conditions are perceived to be outside of one's control or that little control can be exercised over the situation, then reliance on emotion-focused approach strategies are often more adaptive than reliance on problem-focused coping [41]. In addition, it appears that positive reframing or cognitive re-appraisal can help even low-resilient people effectively recover from negative emotional experiences [42].

Self-blame is an avoidance coping mechanism in which an individual blames himself for the stressful or adverse situation and possibly for the resulting stress. This personal assumption of responsibility occurs even though the individual may have had nothing to do with causing the event. In some cases, the individual thinks of methods they might have employed to avoid the event, and then blame themselves for not having the foreknowledge to circumvent the adverse event. In addition, assumption of responsibility can result in self-blame. Self-blame reflects a belief in one's perceived control over a situation or event. Self-blame is most often understood to be a dysfunctional coping strategy as it does not assist in alleviating either the emotional distress or the cause of the stress, but instead focuses one's attention elsewhere (on themselves) and increases resultant stress and suffering. For example, high levels of self-blame are associated with vulnerability to major depressive disorder [43] and with Posttraumatic Stress Disorder (PTSD) [44]. The Diagnostic and Statistical Manual of Mental Disorders, fifth edition (DSM-5) acknowledges "persistent, distorted cognitions about the cause or consequences of the traumatic event(s) that lead the individual to blame himself/herself or others" among the diagnostic criteria of PTSD [45] (309.81(F43.10), p.272). Nazarov and colleagues [44] described guilt and shame as interrelated concepts that are associated with selfblame. They pointed out that in military populations, guilt and shame are linked with suicide and suicidal ideation [46-48], and have been identified as leading causes of seeking U.S. Veterans Administration mental health services [49]. Our finding that less self-blame and greater positive reframing predicted higher resilience for those in active military service points to an apparent perception that stressors are outside of their direct control, but that growth and opportunity are conceivable. Placing individuals with this combined style of coping in positions of targeted authority may be of assistance in developing teams and organizations that are resilient, however research is necessary to test this hypothesis. Additionally, integration of these results into current resilience training may enhance personal resilience, that is, adding instruction in how to alter one's coping strategies to include the use of positive reframing and cease or decrease the use of self-blame would likely enhance one's personal resilience.

\subsubsection{Prediction of resilience among military veterans}

In addition to less self-blame, longer time-inservice and greater use of humor were predictive of veterans' higher resilience. Longer time-in-service lends itself to the establishment of greater camaraderie among those with similar experiences. Given the positive impact of leadership and unit cohesion in promoting resilience [50], one possible contribution to the increase in PTSD rates among reservists is their relative isolation from others with similar experiences [51]. For example, active duty and reservists have been shown to have similar rates of PTSD and related symptoms following deployment to Operations Enduring Freedom and Iraqi Freedom; however, shortly after deployment the rates for reserve personnel increased, while the rates for active duty did not [51]. Additionally, effective interventions to promote mental health and resilience following disaster include assisting survivors by promoting self-efficacy and community participation, especially in rebuilding efforts [52]. Military leadership, unit cohesion, targeted mental health assistance, as well as oppor- 
tunities to rebuild forces and assist fellow service members would likely be more readily available to active duty service members, than to reservists who returned to their civilian community. The impact of time-in-service may also reflect the fact that resilience and coping strategies are not static, and they may improve as a person gains more experience. For example, as pediatric oncology nurses [53] gained more experience at work (beginning compared with 18 months and after), they developed more coping strategies for dealing with difficult situations, were more confident with their professional skills, made better use of their knowledge about their surroundings to reduce stressors, and were more comfortable with their team members in accepting more support from them.

Humor is a form of active coping that bolsters one's mood, alleviating emotional distress [54], without impacting the stressor itself. Humor can serve as a buffer against depression [55] and has been shown to be a moderator of stress [56]. According to Wooten [57], humor and laughter improve immune responses, enhance perceptual flexibility and can offset the effects of stress. Used judiciously, humor has been suggested as potentially having an important impact on resilience following trauma [58], although more research is needed. Positive coping humor has been found to assist with burnout and PTSD among firefighters [59]. The use of humor within a military culture has not been investigated to our knowledge. Anecdotally, the use of humor as a coping mechanism may be discouraged, with the justification that the military is involved in very serious business and humor may denigrate that message. Military culture promotes the concept of Warrior Ethos and military members take pride in their abilities to deal with difficulties on their own [60]. However, once service members have left active duty, they are free to engage openly in humor as a positive coping strategy. Possible work-related benefits of using humor in coping with one's work life include decreasing stress and demonstrating that accomplishments may be attained in a less stressful, positive atmosphere. Once again, teaching the coping skills that are used by the most resilient veterans in resiliency training programs for veterans would seem to be an expected extension of this research.

\subsection{Resilience and work}

Resilience has been found to be positively related to job satisfaction, work happiness and organiza- tional commitment [61]. Resilience can contribute to employees' commitment to change by engendering positive emotions during organizational change [62]. For a review of the components of resilience from the Resilience Scale [1] and their potential positive impact on the workplace, see Part I of this article series in this journal [5].

The influence of coping on resilience is considerable and it appears that coping strategies can be learned. Army soldiers who received brief coping skills intervention reported more helpful causal attributions that led to more realistic expectations of control, less self-blame and better psychological adjustments [41], demonstrating the beneficial effects of training in coping skills.

Ineffective coping can also be learned, potentially developing through repetition [63]. That is, if a person experiences an untoward event and responds in a protective, yet ineffective, manner a few times, then a conditioned response can begin to develop. In the future, a situational trigger is likely to yield similar results. This conditioned response may need to be deconditioned. Ledoux and Gorman [63] suggested those with PTSD have incurred such persistent emotional conditioning in the form of "memories that seize control of mental life and behavior" (p. 1955), but they submit these responses can be rerouted through the learning of adaptive coping. Organizations may need to train employees on how not to use dysfunctional coping with their difficult situations and how to engage more positive coping strategies [64]. Developing resilience does not happen in a vocational vacuum, as one's family can influence their resilience building [65, 66]. Moreover, individual resilience is perhaps only one part of developing team and organizational resilience.

Studies have discussed the factors that promote resilience beyond the individual level, such as with families, organizations, or communities [67, 68]. In a team setting, leaders' confidence, intellectual stimulation, individualized consideration, and contingent award systems have been positively associated with subordinate resilience [69]. In a workplace, support from peers, team members, and managers, and company culture are all factors that contribute to employee resilience [70].

\subsection{Limitations}

The data collected in this study were from a cross-section of a population at a particular point in time, thus causal relationships cannot be determined. 
Additional research is suggested to investigate the development of coping processes and resilience over time. Self-report measures used in this study made it possible for the participants to respond with a bias for social desirability, meaning the participants may have responded to the questionnaire items to make a better impression on other people. This limitation was countered by clearly removing identifiers from individual responses, and making research participants aware of this counter-measure. No supervisors or individuals that might have an impact on participants' careers were permitted to be in attendance during testing or have access to participants' responses. Finally, the results in this study are from military participants and veterans, under non-deployment conditions. Caution should be used in applying these results to other populations.

\section{Conclusions and recommendations}

The results from the current study demonstrate that the U.S. military active service members and veterans in this population used active, positive emotionfocused and problem-focused coping techniques. Moreover, for active service members, greater positive reframing and less self-blame predicted higher resilience, while longer time-in-service, greater use of humor and less self-blame predicted veterans' resilience. The potential impacts of these results in a work setting were discussed. These results suggest that:

- Resiliency training programs for active duty service members incorporate teachings on how to increase positive reframing and decrease the use of self-blame as coping strategies

- Resiliency training programs for military veterans integrate teachings on how to increase humor and decrease the use of self-blame as coping strategies

- Consideration be given to placing individuals with greater resilience into key positions to serve as role models and potentially improve organization resilience

- Further research be conducted focusing on the - differences between coping strategies employed before, during, and following exposure to trauma, both in the short and longer terms

- impact of coping strategies on individual and organizational resilience

\section{Acknowledgments}

This research was supported in part by the U.S. Army Research Program Office. Our appreciation is offered to our colleagues Gary L. Boykin, Rebekah L. Tree and Angela D. Jeter. Special thanks are offered to the participants who volunteered their time in order to increase the knowledge-base and assist their fellow service men and women.

\section{Disclaimer}

The views expressed in this article are those of the authors and do not reflect the official policy or position of the Department of the Army, Department of Defense, or the U.S. Government.

\section{Conflict of interest}

The authors have no conflict of interest to report.

\section{References}

[1] Wagnild GM. The Resilience Scale User's Guide: For the US English Version of the Resilience Scale and the 14-item Resilience Scale (RS-14) (version 3.2). Guinn PE, editor. Worden: Montana. Resilience center; 2011.

[2] Wagnild GM, Young HM. Development and psychometric evaluation of the Resilience Scale. Journal of Nursing Measurement 1993;1(2):165-78.

[3] Carver CS. You want to measure coping but your protocol'too long: Consider the brief cope. International Journal of Behavioral Medicine 1997;4(1):92-100.

[4] Schoon I, Bynner J. Risk and resilience in the life course: Implications for interventions and social policies. Journal of Youth Studies 2003;6(1):21-31.

[5] Rice V, Liu B. Personal resilience and coping with implications for work. Part I: A review. Work. (2016).

[6] Lazarus RS, Folkman S. Stress, Appraisal, and Coping. New York, NY: Springer Publishing Company; 1984.

[7] Moos RH, Schaefer J. Coping resources and processes: Current concepts and measures. In: Goldberger L, Breznitz S. editors. Handbook of stress: Theoretical and clinical aspects. 2nd ed. New York: MacMillan; 1993: 234-57.

[8] Sharkansky EJ, King DW, King LA, Wolfe J, Erickson DJ, Stokes LR. Coping with Gulf War combat stress: Mediating and moderating effects. Journal of Abnormal Psychology 2000;109:188-97.

[9] Wolfe J, Keane TM, Kaloupek DG, Mora CA, Wine P. Patterns of positive readjustment in Vietnam combat veterans. Journal of Traumatic Stress 1993;6:179-93.

[10] Rice VJ. Unpublished Data. 2015

[11] Wagnild GM, Young HM. Development and psychometric evaluation of the Resilience Scale. Journal of Nursing Measurement 1993;1(2):165-78. 
[12] Carver CS, Scheier MF, Weintraub JK. Assessing coping strategies: A theoretically based approach. Journal of Personality and Social Psychology 1989;56(2):267.

[13] Cooper C, Katona C, Livingston G. Validity and reliability of the brief COPE in carers of people with dementia: The LASER-AD Study. The Journal of Nervous and Mental Disease. 2008;196(11): 838-43.

[14] Baiocchi D. Measuring Army Deployments to Iraq and Afghanistan. Santa Monica, California: RAND Corporation; 2011.

[15] Wagnild GM. A review of the Resilience Scale. Journal of Nursing Measurement 2009;17(2):105-13.

[16] Hammond C. How education makes us healthy. London Review of Education 2003;1(1):61-77.

[17] Ross CE, Mirowsky J. Refining the associating between education and health: The effects of quantity, credential, and selectivity. Demography 1999;36(4):834-51.

[18] Grossman M, Kaestner R. Effects of education on health. In: Behrman JR, Stacy N, editors. The Social Benefits of Education. Ann Arbor, MI: University of Michigan Press; 1997.

[19] Rosebush PA. Psychological intervention with military personnel in Rwanda. Military Medicine. 1998; 163(8):559563.

[20] Romero DH, Riggs SA, Ruggero C. Coping, Family Social Support, and Psychological Symptoms Among Student Veterans. Journal of Counseling Psychology. [Advance Online Publication] 2015 Feb; Available from http://dx.doi.org/10.1037/cou0000061.

[21] Esteve R, Ramirez-Maestre C, Lopez-Martinez AE. Adjustment to chronic pain: The role of pain acceptance, coping strategies, and pain-related cognitions. Ann Behavioral Medicine 2007;33(2):179-88.

[22] Lambert NM, Graham SM, Fincham FD, Stillman TF. A changed perspective: How gratitude can affect sense of coherence through positive reframing. The Journal of Positive Psychology 2009;4(6), 461-70.

[23] Fredrickson BL. The role of positive emotions in positive psychology: The broaden-and-build theory of positive emotions. American Psychologist 2001;56(3):218-26.

[24] Stober J, Janssen DP. Perfectionism and coping with daily failures: Positive reframing helps achieve satisfaction at the end of the day. Anxiety, Stress and Coping 2011;24(5): 477-97.

[25] Lambert NM, Fincham FD, Stillman TF. Gratitude and depressive symptoms: The role of positive reframing and positive emotion. Cognition and Emotion. 2011; 00(00), 1-19. Available from Psychology Press: http://www. psypress.com/cogemotion.

[26] Zacharias DR, Gilg CA, Foxall MJ. Quality of life and coping in patients with gynecologic cancer and their spouses. Oncology Nursing Forum 1993;21(10): 1699-1706.

[27] Koenig HG, McCullough ME, Larson DB. Handbook of religion and health. Oxford: Oxford University Press; 2001.

[28] Patterson E. Military Chaplains in Afghanistan, Iraq, and Beyond: Advisement and Leader Engagement in Highly Religious Environments. Lanham, MD: Rowman and Littlefield; 2014.

[29] Sterner WR, Jackson-Cherry LR. The Influence of Spirituality and Religion on Coping for Combat-Deployed Military Personnel. Counseling and Values 2015;6(1): 48-66.

[30] Lee M, Nezu AM, Nezu CM. Positive and negative religious coping, depressive symptoms, and quality of life in people with HIV. Journal of Behavioral Medicine 2014;37(5):92130 .

[31] Tedeschi RG, Calhoun LG. Trauma and transformation: Growing in the aftermath of suffering. Thousand Oaks, CA: Sage; 1995

[32] Bam VB, Oppong GA, Ibitoye MB. Stress and coping mechanisms of nursing students during clinical practice in Ghana. Journal of Science and Technology 2014;34(2):50-59.

[33] Briscoe JP, Henagan SC, Burton JP, Murphy WM. Coping with an insecure employment environment: The differing roles of protean and boundaryless career orientations. Journal of Vocational Behavior 2012;80(2):308-16.

[34] Rothmann S, Jorgensen LI, Hill C. Coping and work engagement in selected South African organizations. SA Journal of Industrial Psychology 2011;37(1):1-11.

[35] Aldwin CM. Does age affect the stress and coping process? Implication of age differences in perceived control. J Gerontology 1991;46:174-80.

[36] Hertel G, Rauschenbach C, Thielgen MM, Krumm S. Are older workers more active copers? Longitudinal effects of age-contingent coping on strain at work. Journal of Organizational Behavior 2015;36(4):514-47.

[37] Carstensen LL, Turan B, Scheibe S, Ram N, ErsnerHershfield H, Samanez-Larkin GR, Brooks KP, Nesselroade JR. Emotional experience improves with age: Evidence based over 10 years of experience sampling. Psychol Aging 2011;26(1):21-33.

[38] Meléndez JC, Mayordomo T, Sancho P, Tomás JM. Coping strategies: Gender differences and development throughout life span. The Spanish Journal of Psychology 2012;15(03):1089-98.

[39] Felsten G. Gender and coping: Use of distinct strategies and associations with stress and depression. Anxiety, Stress, and Coping: An International Journal 1998;11(4):289-309.

[40] Deelstra JT, Peeters MC, Schaufeli WB, Stroebe W, Zijlstra FR, van Doornen LP. Receiving instrumental support at work: When help is not welcome. Journal of Applied Psychology 2003;88(2):324-31.

[41] Cohn A, Pakenham K. Efficacy of a cognitivebehavioral program to improve psychological adjustment among soldiers in recruit training. Military Medicine 2008;173(12):1151-57.

[42] Tugade MM, Fredrickson BL. Resilient individuals use positive emotions to bounce back from negative emotional experiences. Journal of Personality and Social Psychology 2004;86(2):320-33.

[43] Green S, Moll J, Deakin JFW, Hulleman J, Zahn R. Proneness to decreased negative emotions in major depressive disorder when blaming others rather than oneself. Psychopathology 2013;46(1): 34-44.

[44] Nazarov A, Jetly R, McNeely H, Kiang M, Lanius R, McKinnon MC. Role of morality in the experience of guilt and shame within the armed forces. Acta Psychiatrica Scandinavica 2015;1-16.

[45] American Psychiatric Association. Diagnostic and statistical manual of mental disorders, (DSM- $\left.{ }^{\circledR}\right)$. Washington DC: American Psychiatric Publishing; 2013.

[46] Bryan CJ, Ray-Sannerud B, Morrow CE, Etienne N. Guilt is more strongly associated with suicidal ideation among military personnel with direct combat exposure. Journal of Affective Disorders 2013;148:37-41.

[47] Bryan CJ, Morrow CE, Etienne N, Ray-Sannerud B. Guilt, shame, and suicidal ideation in a military outpatient clinical sample. Depress Anxiety 2013;30(1):55-60.

[48] Jakupcak M, Cook J, Imel Z, Fontana A, Rosenheck R, McFall M. Posttraumatic stress disorder as a risk factor 
for suicidal ideation in Iraq and Afghanistan War veterans. Journal of Traumatic Stress 2009;22(4):303-06.

[49] Fontana A, Rosenheck R. Trauma, change in strength of religious faith, and mental health service use among veterans treated for PTSD. The Journal of Nervous and Mental Disease 2004;192:579-84.

[50] MacManus D, Jones N, Wessely S, Fear NT, Jones E, Greenberg N. The mental health of the UK Armed Forces in the 21st century: Resilience in the face of adversity. J R Army Med Corps Published Online First: downloaded from jramc.bmj.com on 25 April 2015.

[51] Griffith J. Citizens coping as soldiers: A review of deployment stress symptoms among reservists. Military Psychology 2010;22(2): 176-206.

[52] Herman H. Promoting Mental Health and Resilience after a Disaster. Journal of Experimental and Clinical Medicine 2012;4(2):82-87.

[53] Hinds PS, Quargnenti AG, Hickey SS, Mangum GH. A comparison of the stress-response sequence in new and experienced pediatric oncology nurses. Cancer Nursing 1994;17(1):61-71.

[54] Bonanno GA. Loss, trauma, and human resilience: Have we underestimated the human capacity to thrive after extremely aversive events? American Psychologist 2004;59(1):20-28.

[55] Fredrickson BL, Tugade MM, Waugh CE, Larkin GR. What good are positive emotions in crisis? A prospective study of resilience and emotions following the terrorist attacks on the United States on September 11th, 2001. Journal of Personality and Social Psychology 2003;84(2):365-76.

[56] Abel MH. Interaction of humor and gender in moderating relationships between stress and outcomes. The Journal of Psychology 1998;132(3):267-76.

[57] Wooten P. Humor as an antidote for stress. Holistic Nursing Practice 1996;10(2):49-55.

[58] Kuiper NA. Humor and resiliency: Towards a process model of coping and growth. Europe's Journal of Psychology 2012;8(3):475-91.

[59] Sliter M, Kale A, Yuan Z. Is humor the best medicine? The buffering effect of coping humor on traumatic stressors in firefighters. Journal of Organizational Behavior. 2013; Published online in Wiley Online Library (wileyonlinelibrary.com), retrieved 25 April 2015.
[60] Cole RF. Understanding military culture: A guide for professional school counselors. The Professional Counselor 2014;4:497-504.

[61] Youssef CM, Luthans F. Positive organizational behavior in the workplace the impact of hope, optimism, and resilience. Journal of Management 2007;33(5):774-800.

[62] Shin J, Taylor MS, Seo MG. Resources for change: The relationships of organizational inducements and psychological resilience to employees' attitudes and behaviors toward organizational change. Academy of Management Journal 2012;55(3):727-48.

[63] LeDoux JE, Gorman JM. A call to action: Overcoming anxiety through active coping. Am J Psychiatry 2001;158(12):1953-55.

[64] Day AL, Livingstone, HA. Chronic and acute stressors among military personnel: Do coping styles buffer their negative impact on health? Journal of Occupational Health Psychology 2001;6(4): 348-60.

[65] Huebner AJ. Advice to the therapists working with military families. National Council on Family Relations [Internet]. 2013. Available from https://www.ncfr.org/ncfr-report/ focus/military-families/advice-therapists.

[66] Russo TJ, Fallon MA. Coping with Stress: Supporting the Needs of Military Families and Their Children. Early Childhood Education Journal. 2014;1-10.

[67] Meredith LS, Sherbourne CD, Gaillot SJ. Promoting psychological resilience in the US military. Santa Monica, CA: Rand Corporation; 2011

[68] Kirmayer LJ, Dandeneau S, Marshall E, Phillips MK, Williamson KJ. Rethinking resilience from indigenous perspectives. Canadian journal of psychiatry. Revue Canadienne de Psychiatrie 2011;56(2):84-91.

[69] Harland L, Harrison W, Jones JR, Reiter-Palmon R. Leadership behaviors and subordinate resilience. Journal of Leadership \& Organizational Studies 2005;11(2):2-14.

[70] Bardoel EA, Pettit TM, De Cieri H, McMillan L. Employee resilience: An emerging challenge for HRM. Asia Pacific Journal of Human Resources 2014;52(3):279-97. 